REVIEWS

\title{
Clinical education of nurse practitioner students: Identifying incentives, barriers, and working models to develop sustainable preceptorships
}

\author{
Lindsay F. Davis, Amy E. Fathman \\ College of Nursing, University of Cincinnati, Cincinnati, OH, United States
}

Received: March 1, 2018

DOI: $10.5430 /$ jnep.v8n9p18

\author{
Accepted: April 10, 2018 \\ Online Published: April 16, 2018 \\ URL: https://doi.org/10.5430/jnep.v8n9p18
}

\begin{abstract}
The purpose of this article is to discuss ongoing barriers nurse practitioner (NP) programs face securing clinical education opportunities, identify incentives to precept, and introduce working models to sustain quality placements. A comprehensive review of literature related to NP preceptorships was performed. Commonly identified barriers included lack of compensation and decreased productivity. Motivating factors included a desire to give back to the profession and credit toward recertification. Working models to establish academic practice partnerships, streamline patient schedules, and prepare preceptors were shown to positively impact the precepting experience. Novel approaches to NP clinical education are necessary to create robust and sustainable learning opportunities.
\end{abstract}

Key Words: Nurse practitioner students, Graduate nursing preceptorship, Preceptor incentives, Preceptor motivation, Interprofessional education, Graduate nursing education

\section{INTRODUCTION}

The Affordable Care Act was enacted in 2010, expanding healthcare coverage for millions of previously uninsured Americans. As a result of this expansion in coverage, an unprecedented number of United States (US) citizens sought healthcare services from primary care providers. It is predicted that by 2020 there will be a shortage of over 20,000 primary care providers, due largely in part to the aging and growing population. ${ }^{[1]}$ An insufficient number of physicians are entering the primary care workforce resulting in a higher demand for providers to serve this population of patients. With this increased demand for primary care providers, nurse practitioners (NPs) have a greater opportunity than ever to expand their role in healthcare delivery. Acknowledgement of this need has led to higher enrollment at universities and schools of nursing offering NP programs. In the decade between 2002 and 2012, an additional 57 nursing schools offered NP programs resulting in a $215 \%$ increase in enrollment. ${ }^{[2]}$ With record high enrollment comes the demand for providers who are qualified to precept students. The ability to accommodate these students relies not only on an adequate number of full time faculty, but also volunteer clinical faculty willing to serve as preceptors.

NP education has historically depended on preceptors to provide quality clinical experiences for the student. Preceptors are typically volunteers within the healthcare system who invest in the mentorship and supervision of students over the

*Correspondence: Lindsay F. Davis; Email: davis2lf@ucmail.uc.edu; Address: College of Nursing, University of Cincinnati, 3110 Vine Street, Cincinnati, OH, United States. 
course of a specified timeframe. ${ }^{[2,3]}$ Qualified NP student preceptors include NPs, Certified Nurse Midwives (CNMs), and physicians. Steady growth of NP student enrollment over the past decade, increased numbers of NP distance learning educational programs, and competition with multidisciplinary health sciences programs has resulted in a shortage of clinical preceptors. ${ }^{[2,4]}$ The growing problem of insufficient numbers of qualified preceptors has become a threat to NP programs across the country. In 2015, the American Association of Colleges of Nursing (AACN) recognized that $96 \%$ of program respondents were moderately or very concerned about the number of clinical sites available for students. ${ }^{[4]}$ Increasing demands for provider productivity and a growing number of students seeking clinical site opportunities have prompted NP programs to evaluate factors contributing to successful recruitment and retention of quality preceptors. ${ }^{[5-7]}$ Providers report experiencing many barriers that discourage them from accepting NP students. ${ }^{[2,7-9]}$ Examining such barriers and developing approaches that address preceptor concerns may motivate those who are apprehensive about supporting clinical education opportunities for students. Identifying motivators to precept is necessary to create working academic-practice partnerships (APPs). The purpose of this article is to discuss ongoing barriers NP programs face securing clinical education opportunities, identify incentives to precept, and introduce working models to sustain quality placements.

\section{METHODS}

The search strategy included a comprehensive, nonexhaustive literature review of the incentives, barriers, and working models of NP preceptorships. Literature was reviewed for qualitative and quantitative research, discussion articles, reviews, and reports related NP clinical education. Key words included nurse practitioner students, preceptorship, preceptor incentives, preceptor motivation, and graduate nursing education. The search for related literature was performed through CINAHL, PubMed, and Scopus.

Inclusion criteria consisted of peer-reviewed articles, availability in full-text, and published in the English language. Literature discussing preceptorship with other healthcare professions was included if it pertained to the topic. Articles prior to 2007 were excluded with the exception of a 2001 article considered by the authors to be a sentinel contribution to the preceptorship issue. Articles containing keywords were reviewed in the preliminary search in an effort to identify pertinence to the topic. The search method resulted in a total of forty relevant articles. Abstracts of these articles were reviewed to determine if the article was pertinent to the topic and then examined for inclusion and exclusion criteria.
A total of eighteen articles met inclusion criteria and were adopted for review. Three common themes emerged from the review of literature to address the problem of securing sustainable preceptorships: barriers, incentives, and working models.

\section{RESUlts}

\subsection{Barriers}

Common barriers discouraging providers from precepting students are outlined in Table 1. ${ }^{[7,10]}$ Time constraints and use of electronic medical records (EMRs) were leading barriers. ${ }^{[2,7-9,11]}$ Pressure to provide care for a higher volume of patients in order to increase productivity and reach reimbursement goals was another key barrier identified in the literature. Accommodating a student increases concern for reduced productivity. Although data is limited supporting the presumption that precepting NP students decreased productivity, preceptors indicated that practice administrators were apprehensive to accept students related to this concern. ${ }^{[9,10]}$

Table 1. Barriers

Barriers to Precepting Identified
- Lack of compensation
- Use of electronic medical records
- Feeling unprepared or unqualified to teach
- Experience level of the student
- Time constraints
- Increasing demand for preceptorship
- Decreased productivity
- Lack of faculty support
- Patient expectations of care by the provider

Use of electronic medical records (EMRs) was widely recognized as a barrier to precepting students. ${ }^{[7-9,11]}$ Providing the student with access to the institution's EMR can not only prolong the onboarding process, but also heighten preceptor concern for decreased efficiency. NP students need assistance navigating EMR systems in order to learn how to document accurately. The variety of systems utilized across a wide range of organizations poses a significant challenge for students who are not exposed to this information in their program. ${ }^{[7]}$ Training and credentialing students in order to access EMR documentation during clinical rotations costs the clinical institution time and money. Many organizations are unwilling to bear that burden. ${ }^{[8]}$

Lack of compensation is a common dissatisfier identified among preceptors. Germano and colleagues noted that compensation for precepting was a significant concern and survey respondents were overwhelmingly in favor of payment due to perceived loss of productivity and time. ${ }^{[9]}$ These find- 
ings were consistent with results from a 2015 study which identified that preceptors felt they should be compensated for working with students. ${ }^{[12]}$ One study identified financial compensation as the leading incentive for serving as a preceptor. ${ }^{[7]}$ According to the 2014 Multi-Discipline Clerkship/Clinical Training Site Survey, $58 \%$ of programs felt increased pressure to provide financial compensation for preceptor recruitment and retention, whereas only $4 \%$ of NP programs actually compensated the preceptor or clinical site. ${ }^{[4]}$ Valid concern exists that paying preceptors may be a conflict of interest for students and NP programs with limited financial resources. ${ }^{[4,13]}$

Additional barriers identified in the literature included lack of training or skills to precept, experience level of the student, and short duration of the clinical experience. ${ }^{[2,8,9]}$ Many preceptors indicated that they do not have the skills or training to serve as an educator which discouraged them from precepting. ${ }^{[11]}$ Preceptors reported little confidence in their ability to recognize the clinical education needs of the student and understand mechanisms for evaluation of student performance. ${ }^{[10]}$ The first clinical rotation was also an unfavorable factor as students are typically less experienced and need more direction. ${ }^{[3,9]}$ Clinical rotations of shorter duration with a limited amount of time spent in each setting was often discouraging to preceptors. ${ }^{[2,3]}$ The time frame of each rotation was dependent upon the clinical hours requirements set by the program and not individualized to the needs of the student or clinical site. Preceptors were required to quickly recognize the learning needs of the student and match patients to these needs under a specified length of time. ${ }^{[3]}$ Shorter rotations place greater pressure on the preceptor to ensure that the student is meeting clinical expectations within a limited time frame.

\subsection{Incentives}

Positive findings from the literature revealed that most preceptors identified the inspiration to teach students and give back to the profession as leading motivators to precept students. Furthermore, they felt precepting facilitated individual learning and adherence to current practice standards. ${ }^{[11]}$ These findings were largely reinforced in a 2014 descriptive, qualitative study of CNMs. The authors identified supporting the profession as the leading motivator to precept, followed by interest in teaching, and remaining current. ${ }^{[9]}$

A 2007 survey of preceptor satisfaction and motivation among pharmacists, advanced practice registered nurses (APRNs), and physician assistants (PAs) identified that intrinsic factors, such as a desire to give back to the profession and underlying inspiration to teach, were more commonly cited motivators for precepting than rewards or incentives. Of the survey respondents, $93 \%$ reported high satisfaction with the precepting experience. Nearly $91 \%$ of respondents indicated they would continue to serve in the preceptor role over the next five years. ${ }^{[6]}$ This study was replicated though a follow up survey in 2011 to evaluate ongoing satisfaction among the same multidisciplinary healthcare professions. ${ }^{[10]}$ Respondents' satisfaction decreased slightly to $91.7 \%$ and intrinsic factors were similarly identified as leading motivators. ${ }^{[5]}$

Data in the literature suggested particular incentives may motivate providers to commit to the preceptor role. An inventory of incentives that were most commonly recognized is outlined in Table 2. Leading incentives included credit toward recertification and tuition vouchers. ${ }^{[2]}$ Precepting offers NPs an opportunity to earn credit toward recertification through the American Nurses Credentialing Center (ANCC) and the American Academy of Nurse Practitioners (AANP), the two main nationally certifying organizations for NPs. The ANCC allows NPs to meet one of eight categories for renewal when precepting students for 120 hours or more. ${ }^{[14]}$ The AANP certification board allows a maximum of 25 nonpharmacology continuing education (CE) credits in exchange for 125 preceptor hours. ${ }^{[15]}$ Pediatric NPs are also offered an opportunity to earn credit toward recertification through the Pediatric Nursing Certification Board and ANCC. ${ }^{[14,16]}$ The American Midwifery Certification Board awards preceptors ten contact hours toward recertification for precepting nursemidwifery students for a minimum of 90 hours. ${ }^{[17]}$ Tuition remission is attractive to preceptors who desire to further their education. ${ }^{[2]}$ Universities offering tuition remission may entice providers who have interest in pursuing a dual certification or terminal degree. Text books, library access, and $\mathrm{CE}$ offerings were also identified as valued incentives as they allow providers to remain up to date with evidence based clinical practice guidelines. ${ }^{[2,7,10]}$

Table 2. Incentives

Incentives and Motivating Factors
- Inherent reasons (i.e. giving back)
- Financial compensation
- Access to library resources
- Adjunct faculty status
- Ability to remain current
- Creditionships toward recertification
- Tuition remission
- Preceptor training
- Continuing education opportunities

A 2015 survey of NPs identified the leading incentive in the category of professional affiliation was adjunct faculty status. ${ }^{[2]}$ Faculty appointments provided university benefits 
such as library access and research opportunities. ${ }^{[8]}$ Sobralske and Naegele identified that preceptors also desired the opportunity to provide input for program curricula. ${ }^{[18]}$ Adjunct faculty status offered greater opportunity for input at the academic level. This dual role aligns with the graduate medical education model in which medical student educators hold joint academic and clinical physician appointments within academic health centers. Physicians participating in such joint appointments have expressed added value to their practice role. ${ }^{[8]}$

Findings in the literature supported formal instruction from the university or faculty member as an important component in the process of creating a positive experience for both the preceptor and student. ${ }^{[12,19]}$ Preceptors valued input and guidance from seasoned faculty who have a foundation in academia. Formal instruction such as preceptor workshops addressed the barrier related to lack of preceptor confidence. Transparent guidelines for the preceptor eliminated ambiguity and set the standard for the clinical experience while providing support in the educator role. ${ }^{[3,10]}$ Preceptors felt that establishing relationships with faculty and maintaining open lines of communication were paramount to a successful partnership. ${ }^{[9,11,12]}$ Strong working relationships with faculty increased the likelihood that the preceptor would oblige requests to precept. ${ }^{[10]}$

With an increasing number of programs offering distance learning opportunities, a diverse population of students now represent universities and institutions across the country. These geographic challenges further complicate the coordination of clinical opportunities for students. ${ }^{[18]}$ Preceptors indicated they preferred not to be contacted directly by students and believed it was the responsibility of the university to arrange clinical placements. ${ }^{[9]}$ Many NP programs designate faculty to coordinate clinical placements, identify learning needs, and ensure a streamlined process. This was appealing to preceptors and clinical sites because the gap in communication was closed with an appointed contact within the academic institution. The faculty coordinator provided direct preceptor support to address student concerns in a timely manner. ${ }^{[18]}$ A designated point of contact limited the number of student inquiries related to clinical opportunities at the site which was cumbersome to the office staff. ${ }^{[8]}$

Preceptors also desired to know the experience level of the student to assist them in planning the practicum experience. ${ }^{[9]}$ Information about the student, such as a biographical sketch and current curriculum vitae (CV), was requested by preceptors prior to committing to the role. The CV helped the preceptor anticipate the learning needs of the student prior to the clinical experience. ${ }^{[18]}$

\subsection{Working models}

Models to improve the precepting experience were examined in an effort to identify successful strategies for establishing new NP clinical education opportunities and retain current preceptors. Current trends suggest formation of APPs, use of scheduling strategies, preceptor techniques, and incorporation of interprofessional education (IPE) as effective models for practice. ${ }^{[3,19,20]}$

\subsubsection{Academic practice partnerships}

The focus of NP clinical education recently transitioned to building sustainable APPs in order to improve the quality and quantity of clinical placements. NP programs established successful APPs by demonstrating appreciation, building stakeholder relationships, assuring student preparedness, and streamlining the evaluation process. ${ }^{[21]}$ Schaffer, Schoon, and Brueshoff developed the partnership engagement model in 2017 which served as a guide for organizing clinical experiences for nursing students. Relationships between nursing faculty, clinical partners, and students were supported by standardized attributes that promoted continuous engagement. The seven attributes identified in the model included planning and flexibility, shared knowledge, role preparation, expertise, collaboration, communication, teaching-learning tools, and accountability. Continuous engagement involved face-to-face meetings to maintain relationships, faculty presence in the clinical setting, and promotion of student participation. Students were welcomed into the clinical environment and encouraged to ask questions and provide feedback about their clinical experience. Use of this model facilitated creation of positive relationships between universities and clinical preceptors leading to APPs. ${ }^{[20]}$

\subsubsection{Scheduling strategies and preceptor education tools}

Creative scheduling strategies have been suggested to improve preceptor efficiency. Examples included focused half days, wave scheduling, and appointment modifications. Focused half days allow the student to select a designated number of patients to see while concentrating on a particular population with respect to age, co-morbidities, or student identified learning objectives. This enables the student to provide independent care to a limited number of patients while allowing the preceptor ample time for all scheduled encounters. While the number of student patient encounters is limited, focused half days scheduling allows for a more autonomous student experience. Wave scheduling involves booking two to three patients in the same time slot followed by a short break. This allows the student to see one patient while the preceptor sees the others. The short 10-15-minute break following the scheduling block maintains productivity while preventing the preceptor from falling behind. An additional scheduling modification includes removing one 
morning appointment and one to two afternoon appointments. Blocking time in the schedule is a less desirable option due to its potential impact on productivity and often requires administrative approval. ${ }^{[3]}$

Three structured educational methods, E-tips, One-Minute Preceptor (OMP), and SNAPPS-6, were evaluated for their usefulness as preceptor teaching strategies. E-tips is a webbased preceptor education resource provided in a modular format. The OMP model provides a concise and systematic approach to elicit student knowledge of patient encounters. SNAPPS-6 is a six step approach to clinical education in which students summarize findings, narrow the differential diagnosis, analyze subjective and objective data, probe the clinician, plan care management strategies, and select a learning objective related to the case. Findings of a 2017 study indicated that $95.5 \%$ of preceptors recommended the use of E-tips to colleagues and classified the modules as applicable and effective when purposefully incorporated into the preceptor role. Preceptors reported improvement in teaching skills and increased success in the role with implementation of the OMP model. Use of the SNAPPS-6 technique demonstrated improved use of differential diagnosis by students. Students also demonstrated greater effort to ask questions when clarification was needed with use of the SNAPPS-6 technique. Clinical reasoning was improved when structured methods were a component of clinical practice. Utilizing validated and standardized tools promoted an effective learning environment for the preceptor and student. ${ }^{[19]}$

\subsubsection{Interprofessional education}

NP students require educational opportunities which develop interprofessional collaboration skills in order to be effective team members in the evolving health care system. ${ }^{[22]}$ Chen and colleagues examined preceptorship strategies utilized by other professions in the clinical setting compared to APRN education to guide best practice in preceptor training and development. Knowledge gaps related to curricula, goals, and scope of practice for students of other professions were identified. Four teaching methods were identified across interdisciplinary professions based on the level of role differentiation applied to the experience. The undifferentiated approach educated students without regard to their professional skill level. This approach limited opportunities for interprofessional collaboration and understanding of various disciplines. The semi-differentiated approach correctly identified the skill level, but assumptions about learning needs resulted in missed clinical opportunities. In a together but separate approach, preceptors focused on working solely with students from their own profession resulting in limited encounters with other colleagues. The most impactful approach was composed of preceptors who were able to modify their teaching to the level and profession of the student. Some preceptors purposefully recognized differences in student roles while modeling collaboration with interdisciplinary healthcare team members. This was shown to be the most successful approach in the clinical setting and led to the development of an IPE champion, who encouraged students and preceptors to learn from one another. The presence of an IPE champion positively impacted clinical learning opportunities and was the key factor for successful interdisciplinary precepting. Participants noted that patients appreciated a team approach to their care reinforcing the need for collaboration among healthcare professionals. ${ }^{[23]}$

\section{Discussion AND CONCLUSION}

Addressing barriers, incorporating incentives, and identifying working models for NP student preceptorships can lead to sustainable clinical learning opportunities. Identifying new approaches to clinical education that lead to successful recruitment and retention of preceptors is imperative. Cold calls to individual providers by NP students, program faculty, and staff have been ineffective in producing ongoing, sustainable placements which align with curriculum standards. Consistent strategies to maintain open lines of communication and preceptor support throughout the clinical experience should be incorporated into each program. Faculty clinical site visits are strongly encouraged to verify student competency and appropriateness of the clinical site. ${ }^{[24]}$

Time constraints were consistently identified as a leading barrier although data is limited as to whether students truly decrease preceptor productivity. Future studies should examine whether this is a perceived or actual barrier. Incentives need to be evaluated for the financial impact on NP programs, NP students, and clinical sites. Examining the impact of incentives on preceptor satisfaction, commitment, and retention is necessary to foster strong APPs. Working models to improve the clinical education experience should continue to be evaluated for effect on work flow and student learning outcomes. Practical scheduling modifications may improve preceptor satisfaction, but are dependent on practice policies. Integrating interprofessional clinical education practices had a positive effect if preceptors valued a shared teaching and learning experience with students from other disciplines. ${ }^{[23]}$ NP program quality improvement projects would be an ideal forum for evaluating the impact of these interventions on clinical education opportunities.

The impending shortage of primary care providers poses a significant risk to the aging and growing population in need of quality healthcare. NPs are uniquely positioned to fill the need for access to care for millions of US citizens. Studies show NPs provide quality care with patient outcomes 
equal-to or better than physicians. ${ }^{[25]}$ That quality cannot be maintained with subpar clinical education. Objective data measuring the effectiveness of various graduate nursing clinical education models is limited. Strong relationships with regional health care organizations are essential if NP programs hope to move away from the traditional apprenticeship model and create a system of ongoing and appropriate clinical training opportunities for their students. Individualized APPs between NP programs and regional health centers could provide ample opportunities for standardized, immersive, interprofessional, and innovative clinical education experiences.

Record high NP program enrollment intensifies the need for committed preceptors and calls into question the sustainability of the one to one apprenticeship clinical education model to meet work force demands. Current practice suggests that the future of NP represented healthcare depends on dedicated preceptors willing to personally invest in the education of students. An understanding of barriers, incentives, and successful working models for establishing and sustaining preceptorships will allow NP programs to develop standardized processes which ensure their graduates are well prepared to fill the highly anticipated primary care work force gap.

\section{ACKNOWLEDGEMENTS}

The authors would like to acknowledge the University of Cincinnati College of Nursing for supporting this work.

\section{CONFLICTS OF INTEREST Disclosure}

No known conflicts of interest associated with this publication exist.

\section{REFERENCES}

[1] Health Services and Resources Administration. Projecting the supply and demand for primary care practitioners through 2020 in brief [Internet]. 2013 [cited 2017 Nov 21]. Available from: https://bhw.hrsa.gov/sites/default/files/bhw/n chwa/primarycarebrief.pdf

[2] Webb J, Palan Lopez R, Guarino AJ. Incentives and barriers to precepting nurse practitioner students. J Nurse Pract. 2015; 11(8): 782-9. https://doi.org/10.1016/j.nurpra.2015.06.003

[3] Barker ER, Pittman O. Becoming a super preceptor: A practical guide to preceptorship in today's clinical climate. J Am Acad Nurse Pract. 2010; 22(3): 144-9. PMid:20236398 https ://doi .org/10 $.1111 / \mathrm{j} .1745-7599.2009 .00487 . x$

[4] American Association of College of Nursing. White Paper: Reenvisioning the Clinical Education of Advanced Practice Registered Nurses. 2015.

[5] Latessa R, Colvin G, Beaty N, et al. Satisfaction, motivation, and future of community preceptors: What are the current trends. Acad Med. 2013; 88(8): 1164-70. PMid:23807105 https ://doi.org/ 10.1097/ACM. Ob013e31829a3689

[6] Latessa R, Beaty N, Landis S, et al. The satisfaction, motivation, and future of community preceptors: The north carolina experience. Acad Med. 2007; 82(7): 698-703. PMid:17595570 https: //doi.org/10.1097/ACM.0b013e318067483c

[7] Roberts ME, Wheeler KJ, Tyler DO, et al. Precepting nurse practitioner students: A new view-results of two national surveys of nurse practitioner preceptors. J Am Assoc Nurse Pract. 2017; 29: 484-91. https://doi.org/10.1002/2327-6924.12482

[8] Forsberg I, Swartwout K, Murphy M, et al. Nurse practitioner education: Greater demand, reduced training opportunities. J Am Assoc Nurse Pract. 2015; 27(2): 66-71. https ://doi.org/10.1002/23 $27-6924.12175$

[9] Germano E, Schorn M, Phillippi J, et al. Factors that influence midwives to serve as preceptors: An american college of nursemidwives study. J Midwifery Womens Health. 2014; 59(2): 167-75. PMid:24655718 https ://doi.org/10.1111/jmwh. 12175

Published by Sciedu Press
[10] Wiseman R. Survey of advanced practice student clinical preceptors J Nurs Educ. 2013;52(5):253-8. PMid:23495701 https : //doi .or g/10.3928/01484834-20130319-03

[11] Dallaghan G, Alerte A, Ryan M, diatric preceptors Acad Med [Internet]. 2017; 92(8): 1168-74. Available from: http://www.nursecredentialing.o rg/RenewalRequirements.aspx https://doi.org/10.1097/ACM.0000000000001667

[12] Logan B, Kovacs K, Barry T. Precepting nurse practitioner students: One medical center's efforts to improve the precepting process. J Am Assoc Nurse Pract. 2015; 27(12): 676-82. https: //doi.org/10.1002/2327-6924.12265

[13] Farwell A. Practitioner preceptors: A shortage of willing mentors. J Pediatr Heal Care. 2009; 23(3): 198-200. PMid:19401255 https://doi.org/10.1016/j.pedhc.2009.02.009

[14] American Nurses Credentialing Center Certification. 2017 Certification Renewal Requirements [Internet]. 2017 [cited 2018 Jan 10] Available from: http://www.nursecredentialing.org/Renew alRequirements.aspx

[15] American Academy of Nurse Practitioners Certification Board. AAN PCB NP Recertification Certificant Handbook [Internet]. 2017 [cited 2018 Jan 10]. Available from: https ://www. aanpcert.org/res ource/documents/RecertificationHandbook.pdf

[16] Pediatric Nursing Certification Board. CPNP-PC Primary Care Recertification Your Guide for Recertifying for 2018 [Internet]. 2018 [cited 2018 Jan 10]. Available from: https://www.pncb.org/sites/d efault/files/resources/PC_CPNP_Recert_Guide.pdf

[17] American Midwifery Certification Board. Continuing Education Policy [Internet]. [cited 2018 Jan 10]. Available from: http://www .amcbmidwife.org/certificate-maintenance -program/continuing-education-policy

[18] Sobralske M, Naegele L. Worth their weight in gold: The role of clinical coordinator in a family nurse practitioner program. J Am Acad Nurse Pract. 2001; 13(12): 537-44. PMid:11836829 https ://doi.org/10.1111/j.1745-7599.2001.tb00322.x

[19] Bazzell AF, Dains JE. Supporting nurse practitioner preceptor development. J Nurse Pract. 2017; 13(8): 375-82. 
[20] Schaffer M, Schoon P, Brueshoff B. Creating and sustaining an academic-practice partnership engagement model. Public Health Nurs. 2017; 1-9. https ://doi.org/10.1111/phn. 12355

[21] Drayton-Brooks S, Gray P, Turner N, et al. Building clinical education training capacity in nurse practitioner programs. J Prof Nurs. 2017; 1-7. https://doi.org/10.1016/j.profnurs.2017.02.002

[22] Farrell K, Payne C, Heye M. Integrating interprofessional collaboration skills into the advanced practice registrered nurse socialization process. J Prof Nurs. 2015; 31(1): 5-10. PMid:25601240 https://doi.org/10.1016/j.profnurs.2014.05.006

[23] Chen A, Rivera J, Rotter N, et al. Interprofessional education in the clinical setting: A qualitative look at the preceptor's perspective in training advanced practice nursing students. Nurse Educ Pract. 2016; 21: 29-36. PMid:27710811 https://doi.org/10.1016/j.nepr .2016 .09 .006

[24] Brooks MV, Niederhauser VP. Preceptor expectations and issues with nurse practitioner clinical rotations. J Am Acad Nurse Pract. 2010; 22(11): 573-9. PMid:21054630 https://doi.org/10.111 $1 / j .1745-7599.2010 .00560 \cdot x$

[25] Swan M, Ferguson S, Chang A, et al. Quality of primary care by advanced practice nurses: a systematic review. Int J Qual Healthc. 2015; 27(5): 396-404. PMid:26239474 https://doi.org/10.1 093/intqhc/mzv054 